\title{
Emergency-Proof Tourism: The Heritage of Industrial Archaeology in Internal Areas as a Potential for a Sustainable Tourism
}

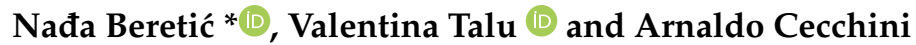

check for

updates

Citation: Beretić, N.; Talu, V.; Cecchini, A. Emergency-Proof Tourism: The Heritage of Industrial Archaeology in Internal Areas as a Potential for a Sustainable Tourism. Sustainability 2021, 13, 3911.

https://doi.org/10.3390/su13073911

Received: 24 March 2021

Accepted: 31 March 2021

Published: 1 April 2021

Publisher's Note: MDPI stays neutral with regard to jurisdictional claims in published maps and institutional affiliations.

Copyright: (c) 2021 by the authors. Licensee MDPI, Basel, Switzerland. This article is an open access article distributed under the terms and conditions of the Creative Commons Attribution (CC BY) license (https:/ / creativecommons.org/licenses/by/ $4.0 /)$.

\author{
Department of Architecture, Design and Urban Planning (DADU), University of Sassari, 07041 Alghero, SS, Italy; \\ vtalu@uniss.it (V.T.); cecchini@uniss.it (A.C.) \\ * Correspondence: nberetic@uniss.it
}

Instead of narrowly protecting the heritage, the UNESCO World Heritage Convention promotes a holistic development approach to respond to new societal challenges. The modern concept of heritage is in line with the contemporary issues of environmental protection and sustainable development. Heritage resources have acquired a significant role in sustainable social, economic, and environmental systems. Since then, the protection and promotion of heritage have aimed to ensure maximum vitality, functions, and wellbeing of present and future generations, especially the local community in which the heritage is located.

The number of UNESCO heritage sites does not increase exponentially, rather permanently. When a place is declared heritage, the future and identity of many people become affected. The global recognition of a unique heritage character provides an excellent position to be noted as a singular and attractive tourist destination, bringing prominence and monetary revenue.

In terms of socioeconomic development, tourism is considered to be one of the most significant phenomena that can boost the local economy. It provides benefits as long as it is compatible with the needs and desires of local communities. Nevertheless, tourism shows numerous paradoxes and, at the same time, enables advantages, tensions, and pressures in the city's functionality. Harmful effects are escalating due to the rapid growth of international and domestic heritage tourism. As the number of visitors increases, so do the negative aspects.

Tourism may seem like a generous "cash machine," but it is a "heavy industry" in reality [1]. In "successful" cases, tourism grows fast, shaping the space and society that takes the form of visitors' demands or their interpretations. The needs and desires of the local population remain uncalculated in projections on urban life. The resulting spatial transformations are usually of low urban quality and without urban life. In addition to cultural and social aspects, numerous indirect effects arise due to uncontrolled tourism growth-over-tourism. This tourism causes further disputes and explicit conflicts affecting changes in the value of the real estate. Modifications in the uses and functions of buildings and neighborhoods followed.

Putting to rent a part of the accommodation, renovating, repurposing neglected real estate units, or abandoning accommodation in a "valuable" area by moving to another, has cascaded, accompanies the growth and evolution of the tourism industry. Effects of profound transformations produce the expulsion or marginalization of residents in large areas of historical cities (in some cases, as in Venice, deep transformations could size the entire historic city core and "lucky" peripheral zones, as the mainland at Venice). The appearance of multi-actor conflicts has increased. Multiple disagreements arise between those who benefit from the phenomenon (residents or former residents) and those who suffer from disadvantages (residents, owners, or renters). Real estate operators skirmish with online travel agencies (OTAs), platform operators, hotel operators, owners, and 
residents. Platform operators clash with national and local public authorities responsible for tax and service management issues. Economic activities aimed at tourism usually do not collide with those aimed at housing. Residents and tourists are at loggerheads over the use of services.

Projections of "tourist desire," driven by their demand, modify the use of land and the environment, obscuring the truthful conditions of urban life.

Unlike other industries, tourism depends on natural, regional, and local resources, moreover, on culture. Thus, the culture became a resource for the tourism industry, estimable and responsible for the engagement, development, and tourism management [2]. Tourism draws on natural and cultural heritage resources but rarely reaches a balance between protecting and developing them.

Even when one thinks of managing and controlling the phenomenon, the outcomes can be ambiguous. Probably the global uniformity of the UNESCO heritage site was not a deliberately created consequence. Yet, UNESCO heritage sites are the subject of "universalism" since cultural globalization follows the economic one. Many UNESCO sites are exposed or overwhelmed by uniformity, which resulted from globalization that opposes the preservation of a unique heritage.

Emergency-proof tourism might turn negative tourism aspects into outstanding opportunities. The Special Issue "Emergency-Proof Tourism: The Heritage of Industrial Archaeology in Internal Areas as a Potential for a Sustainable Tourism" of the journal Sustainability aimed to accept the current COVID-19 pandemic crisis as a challenge and an opportunity to activate heritage resources for sustainable tourism. In this issue, we have collected alternative and sustainable approaches to inland areas and cultural landscapes. Heritage of industrial archaeology was the focus of our interest.

First, we are started from the hypothesis that sustainable tourism can change the controversial relationship between heritage sites and tourism. This hypothesis proves more truthful if we profoundly rethink the pre-pandemic models and forms of mass tourism.

The dramatic growth in tourism before the pandemic emerged, in many cases, direct and indirect damage of environmental, social, or cultural aspects of numerous places, and in the short, medium, or long terms. Recently, protests and mobilizations have risen in many situations due to phenomena caused by excessive tourist pressure-over-tourism.

Sustainable tourism, in which history and culture play a principal role in travel experience, requires an inclusive approach to asset-based economic development with history, culture, and nature. Planning and management of such tourism must reflect economic, environmental, and sociocultural aspects. Accordingly, sustainable heritagebased tourism should examine the diversity of alternative tourism approaches. Aiming to achieve positive effects on local life and preserve heritage, heritage-based sustainable tourism should engage inhabitants and visitors, ensuring a memorable experience.

Some types of tourism are more sustainable in their nature. Tourism related to the recovery of cultural heritage is linked to the so-called industrial archaeology is of this type for several reasons. The renewal process of old industrial regions has proven culture tourism or heritage tourism useful for sustainable local development. The two forms of tourism have much mutual, both being place-based and attracting a similar visitor profile. They focus on experience and deal with the lifestyles of the community that lives at the heritage site.

Second, despite the numerous global economic crisis, tourism has proven to be a resilient sector, moreover, the sector that recovers efficiently since the beginning of the 21st century. The latest data from the United Nations World Tourism Organization (UNWTO), "UNWTO World Tourism Barometer," have shown a decrease in the number of international tourist arrivals by $72 \%$. Asia and the Pacific regions have demonstrated the most affected by COVID-19 during the compared periods January-October of the years 2019 and 2020 [3]. Although tourism has returned to 1990 levels, the UNWTO envisions, in its scenarios, a return to 2019 level in terms of international arrivals in two to four years [3]. Despite current negative trends, the recovery capacity of tourism is ultimately high. Even in a 
state of decay and stagnation, we must not ignore this fact. We should plan for tourism as a sustainable economy that is not exclusively in the service of visitors. In other words, preventing uniformity and celebrating unique heritage features require a place-based local economy that conveys the place of heritage as the creative product and context for daily activities.

Third, the demand for international travel continues to be subdued, while domestic tourism constantly grows. In several large markets, such as China and Russia, domestic air travel demand has generally returned to pre-COVID levels. Domestic tourism, in most cases partially, triggers the recovery of tourist destinations. Due to the UNWTO recent survey, the most positive responses about recovery are coming from Asia and the Pacific (47\%), then the Middle East (33\%), and Europe (27\%) [3,4]. Globally, domestic tourism is over six times bigger than international tourism [4]. The largest domestic tourist markets are India, China, and the United States due to their large population and geographical size. Other major domestic tourist markets include Japan, Brazil, France, and Spain [4].

Without intending to recover the tourism sector or replace foreign tourism, domestic tourism can be an intriguing topic of sustainable tourism. We believe in the powerful potentials of domestic tourism that might bring long-term sustainable futures beyond mitigating the effects of the COVID-19 crisis. Domestic tourism motivates a new conception of tourism. It favors the redistribution of flows of people to larger areas, excluding the possibility of over-tourism. In this way, the current unfortunate situation turns into a superb opportunity for interiors rich in heritage, which usually remain neglected or in the shadow of other well-known and well-maintained tourist destinations.

The sustainable "touristification" of former industrial areas could illuminate inner areas and heritage of industrial archaeology. On the other hand, former industrial sites usually demonstrate fragmentation and deterioration of the heritage so that sustainable tourism could contribute to sustainable territorial development. In this case, sustainable tourism must promote cultural values in territorial cohesion and identity building. This progressive conception defines territory as a complex system of cultural and social interspatial connections. When conceived as a place of heritage and habitat of people, former industrial landscapes require a definition of environmental dimensions, their features and settings, and their spatial organization and connections. Above all, the new concept must define the role of industrial heritage for local communities. In this way, the reinvention of heritage in tourism purposes takes upon particular past and present, strengthening a new territorial coherence between people and heritage sites. Meanwhile, potentially distinctive, memorable, and shareable experiences for visitors will not compromise the local life.

Forth, we used the term "heritage of industrial archeology," which may sound incorrect or seemingly unnecessarily complicated. However, we used this compound knowingly. Our goal was to combine the concepts of industrial heritage and industrial archeology in the industrial landscape, which included the broadest range of understandings.

In this Special Issue, industrial activity refers to industrial manufacturing, industrial, pre-industrial, and proto-industrial productive processes. We encompassed all heritage showing a connection with the former industry, including cultural landscapes and all mixed forms of natural and cultural heritage. Despite our wide-ranging debate on UNESCO heritage, official recognition was not a criterion for inclusion in this Special Issue.

The heritage of industrial archaeology celebrates past industrial activities, profoundly modified landscapes, and lifestyles. Extremely heterogeneous characteristics and features in-between nature and culture [2] turn the heritage into a complex system. Such a complex system necessitates the definition of strategic development priorities, which must consider diversification, compatibility, and intersections of heritage resources. First, heritage resources intersect physically with the economic exploitation of infrastructural connections and time. Second, the point of intersection is qualitative assets of the thematic diversity that the heritage represents. The possibilities of thematic diversity depend on the natural and cultural composition of the landscape and the socioeconomic conditions that shape it. Despite the great potential for networking and shared management of diversified her- 
itage, the heterogeneous character might prove to be an obstacle because it requires high governance capacity [2].

Finally, in this Special Issue, we started a debate on the development strategies associated with the areas marked by an industrial past and their relationships with forms of sustainable tourism. Through a direct or indirect link to tourism, development strategies simultaneously protect heritage and transform the space, ensuring a memorable experience for indigenous people and visitors.

Conflicts of Interest: The authors declare no conflict of interest. The funders had no role in the design of the study; in the collection, analyses, or interpretation of data; in the writing of the manuscript, or in the decision to publish the results.

\section{References}

1. Cecchini, A. Which Tourisms? Which Territories? In Enhancing the City. Urban and Landscape Perspectives; Maciocco, G., Serreli, S., Eds.; Springer International Publisher: New York City, NY, USA, 2009; Volume 6, pp. 277-312. [CrossRef]

2. Beretić, N.; Đukanović, Z.; Cecchini, A. Geotourism as a Development Tool of the Geo-mining Park in Sardinia. Geoheritage 2019, 11, 1689-1704. [CrossRef]

3. UNWTO. UNWTO World Tourism Barometer and Statistical Annex, (English Version); UNWTO: Madrid, Spain, 2020; Volume 18, pp. 1-36.

4. UNWTO. UNWTO Briefing Note-Tourism and COVID-19, Issue 3. Understanding Domestic Tourism and Seizing its Opportunities; UNWTO: Madrid, Spain, 2020. [CrossRef] 